\title{
Investigation of Supra-Harmonics through Signal Processing Methods in Smart Grids
}

\author{
Turgay Yalcin ${ }^{1}$, Muammer Ozdemir ${ }^{1}$ \\ ${ }^{1}$ Ondokuz Mayis University, Electrical\&Electronic \\ Engineering Faculty, Samsun, TURKEY \\ turgay.yalcin@omu.edu.tr, ozdemirm@omu.edu.tr
}

\author{
Pawel Kostyla ${ }^{2}$, Zbigniew Leonowicz ${ }^{2}$ \\ ${ }^{2}$ Wroclaw University of Technology \\ Faculty of Electrical Engineering, Wroclaw, Poland \\ pawel.kostyla@pwr.wroc.pl, leonowicz@ieee.org
}

\begin{abstract}
Nowadays supra-harmonic distortion studies are gaining attention day by day in power quality research area. When handling communication systems especially Power Line Carrier (PLC) systems in frequency range 2- $150 \mathrm{kHz}$, they are suitable for causing electromagnetic interference (EMI) to other systems. This study shows results of analysis employing advanced method called ensemble empirical mode decomposition (EEMD) to describe supra-harmonic distortion. Unlike the traditional method (short time fourier transform- STFT), EEMD gives extensive representation for supra-harmonic components
\end{abstract}

Index Terms-ensemble empirical mode decomposition; power quality; short time fourier analysis; supra-harmonics;

\section{INTRODUCTION}

A novel and significance increasing day by day hazardous risk to smart grid systems called supra - harmonics or emissions in $2 \mathrm{kHz}-150 \mathrm{kHz}$ frequency band. This threat can affect capacitors, lose communication contacts with smart meters. The important single fault source operations from photovoltaic inverters (PVs). Naturally fuel cells, battery chargers also wind turbines, can produce this serious threat [1, 2, 3]. Supraharmonics also disturb domestic appliances, semi-conductor manufacturing devices, medical equipments, security systems even transportation controls. PLC produces low-impedance for emissions in subharmonics frequency range. The highest levels are commonly by virtue of PLC. As a result, power grids are worked out to transfer power at $50 \mathrm{~Hz}$ however, line also carries $2 \mathrm{kHz}-150 \mathrm{kHz}$ electromagnetic components [4, 5, 6, 7, 17]. In this study, National Instruments PWr cRIO Data Recorder was used to acquire distortions in power systems. Sampling frequency was selected $1 \mathrm{MHz}$ for measurements. Table I. gives the information of PV systems components properties. Fig 1 shows PV System at the Faculty of Electrical Engineering Wroclaw University of Technology.

TABLE I. PV SYSTEM COMPONENTS PROPERTIES

\begin{tabular}{|c|c|c|c|}
\hline \hline & $\begin{array}{c}\text { Monocrystalline } \\
\text { c-Si }\end{array}$ & $\begin{array}{c}\text { Polycrystalline } \\
\text { p-Si }\end{array}$ & $\begin{array}{c}\text { The panel } \\
\text { thin-film CIGS }\end{array}$ \\
\hline Efficiency & $14,90 \%$ & $15,50 \%$ & $11,80 \%$ \\
\hline Maximum power & $190 \mathrm{~W}$ & $240 \mathrm{~W}$ & $90 \mathrm{~W}$ \\
\hline $\begin{array}{c}\text { Maximum } \\
\text { voltage }\end{array}$ & $36,5 \mathrm{~V}$ & $30 \mathrm{~V}$ & $60,8 \mathrm{~V}$ \\
\hline $\begin{array}{c}\text { Maximum } \\
\text { current }\end{array}$ & $5,2 \mathrm{~A}$ & $8 \mathrm{~A}$ & $1,48 \mathrm{~A}$ \\
\hline Dimensions & $\begin{array}{c}1580 \times 808 \times \\
35 \mathrm{~mm}\end{array}$ & $\begin{array}{c}1680 \times 1040 \times \\
35 \mathrm{~mm}\end{array}$ & $\begin{array}{c}1196 \times 636 \times \\
36 \mathrm{~mm}\end{array}$ \\
\hline Weight & $17,2 \mathrm{~kg}$ & $20 \mathrm{~kg}$ & $14,5 \mathrm{~kg}$ \\
\hline \hline
\end{tabular}

\begin{tabular}{|c|c|c|c|}
\hline \hline $\begin{array}{c}\text { The angle of } \\
\text { inclination to the } \\
\text { horizontal }\end{array}$ & $\beta=40^{\circ}$ & $\beta=40^{\circ}$ & $\beta=40^{\circ}$ \\
\hline Azimuth & $\gamma=135^{\circ}$ & $\gamma=225^{\circ}$ & $\gamma=135^{\circ}$ \\
\hline
\end{tabular}

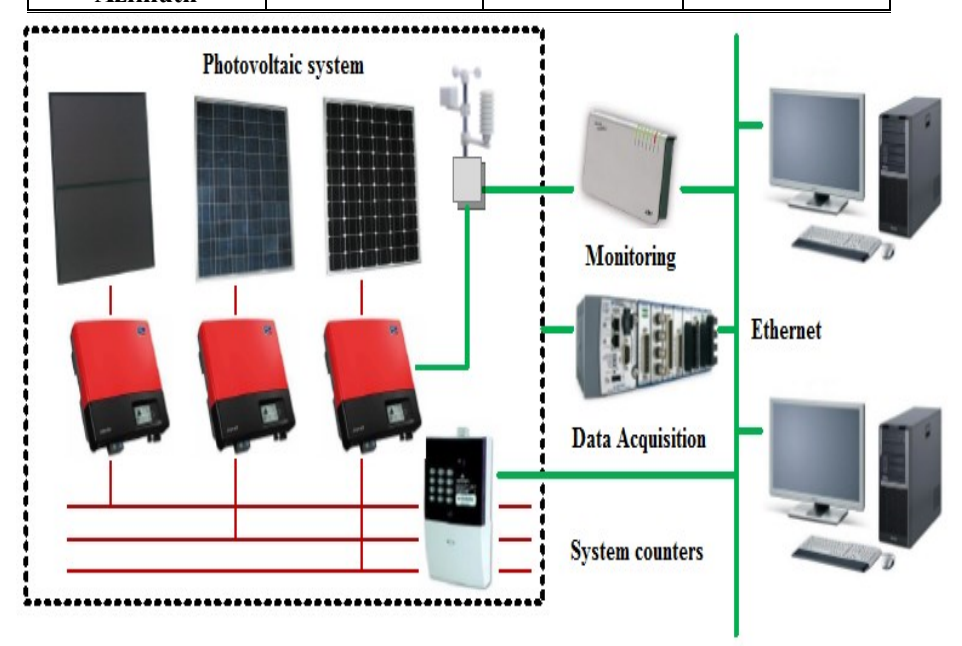

Fig 1. Photovoltaic System at the Faculty of Electrical Engineering Wroclaw University of Technology

\section{Signal PROCESSING METhods}

\section{A. Short Time Fourier Transform}

Traditionally STFT is applied to measured data from domestic appliances and Sunny Mini Central PV inverter. The results from the STFT are presented in a spectrogram. Spectrograms used for signal processing owing to show supraharmonics. STFT has drawbacks about representation magnitude and frequency bands [8]. In algorithm we used STFT with hamming sliding window $(5 \mathrm{~ms}$ ) for decompositon. . Respectively fig 2 and 5 shows STFT spectrograms and $2 \mathrm{~Hz}-$ $120 \mathrm{kHz}$ frequency band for current signals of domestic appliances LCD TV and Laser Printer. 

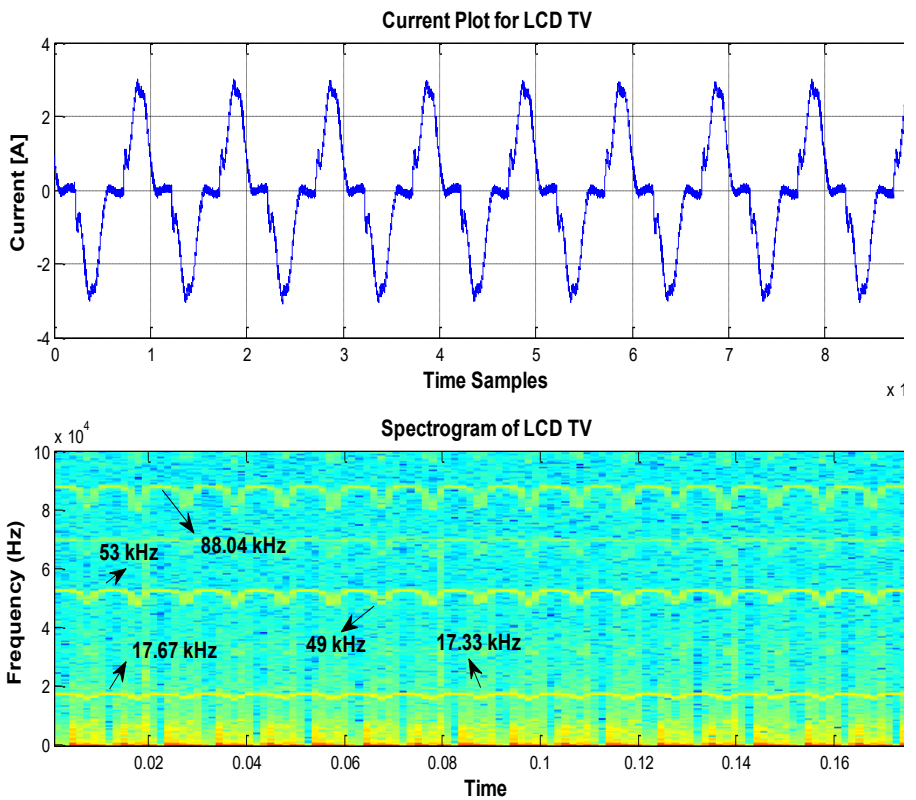

Fig 2. Spectrogram of the current LCD TV

In figure 2 is illustrated constant or continuous frequency emissions at $17.6 \mathrm{kHz}, 53 \mathrm{kHz}$ and $88 \mathrm{kHz}$ bands.

\section{B. Ensemble Emprical Mode Decomposition (EEMD)}

EMD has been profitably performed for non-stationary signal processing. The EMD could decompose the complicated signal function into a number of Intrinsic Mode Functions (IMFs)[9,10,11]. The algorithm has major drawbacks of mode mixing, end effects and etc[12,13,14,15,16]. Therefore, in this work we performed EEMD method for generating IMFs in order to analyze supra-harmonics. We focused on pattern frequency band which is dominated in power grid.

The mathematical background of EEMD algorithm (Fig 3):

i. Add noise, $w n(t)$, to target signal $s_{1}(t)$. $s_{2}(t)=s_{1}(t)+\mathrm{w} n(t)$.

ii. Used EMD $[9,10,11,12,16]$ algorithm for decomposing the final signal $s_{2}(t)$.

iii. Continue steps (i) and (ii) till the trial numbers. When new imf combination $C_{i j}(t)$ is succeeded, predict the ensemble mean of the last intrinsic mode function (IMF). (Selected Nstd: 0 and Number of Ensemble: 1 we used EEMD like EMD.)

The aimed output:

$$
\operatorname{EEMD}\left[c_{j}(t)\right]=\sum_{i=1}^{t n} c_{i j}(t)
$$

tn: trial numbers, $i$ : iteration number and $j$ : imf scale $[13,14$, $15]$.

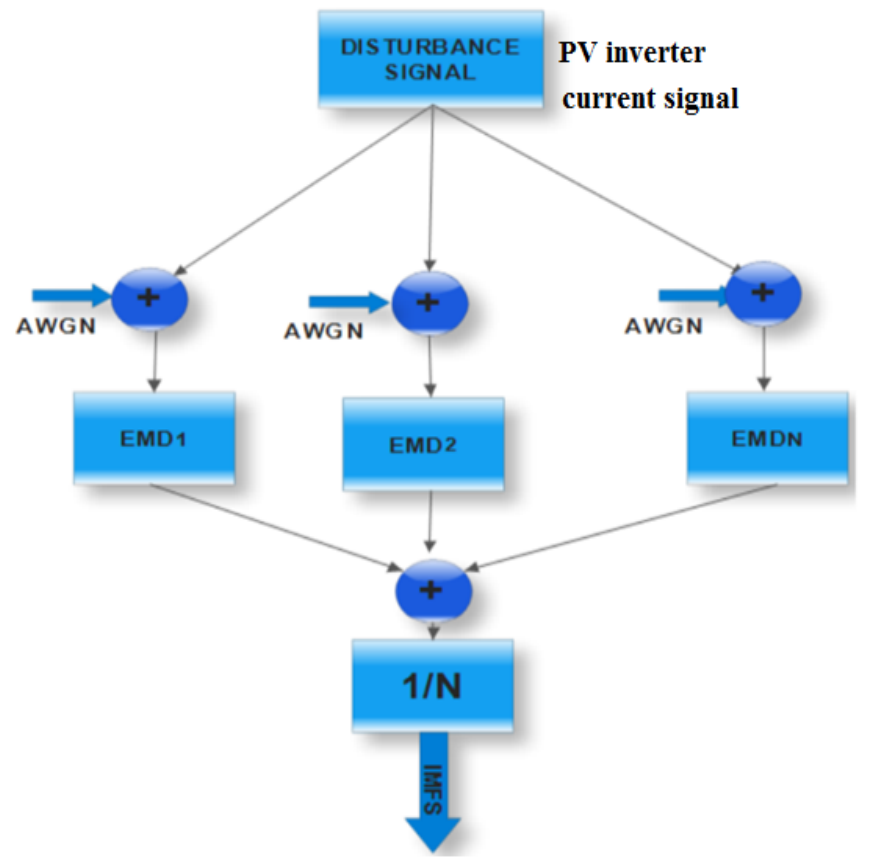

\section{IMF to last IMF (Residual)}

Fig. 3. The representation of the EEMD algorithm[16]

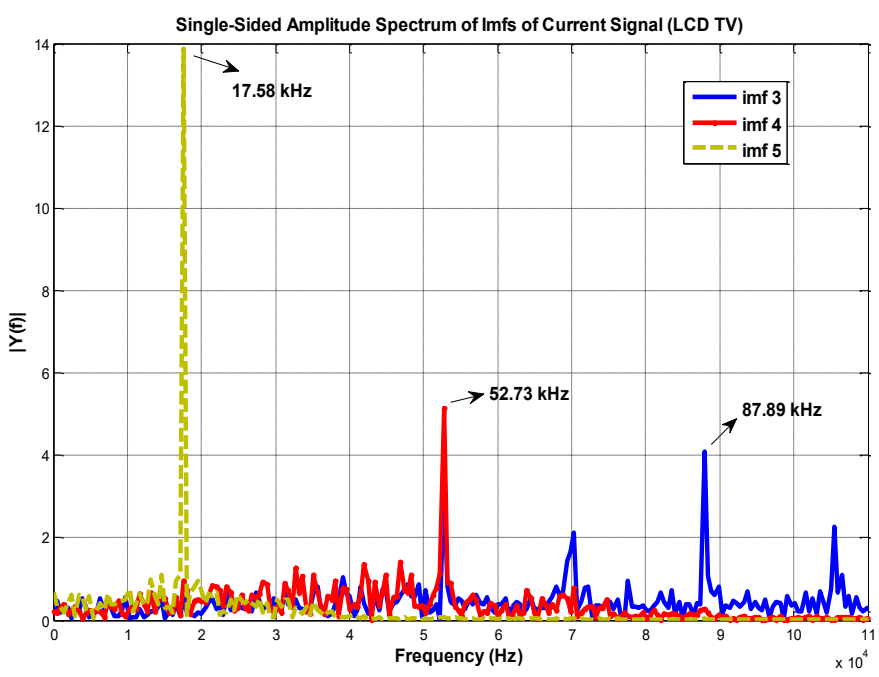

Fig 4. Frequency IMFs components for current of LCD TV

Figure 4 shows the frequency spectrum of IMF 3- IMF 5. When we look for the spectrum it is clearly illustrated that IMF 3 represents the frequency component $(17.58 \mathrm{kHz})$. Moreover, IMF 4 also shows frequency $(52.73 \mathrm{kHz})$ band. 

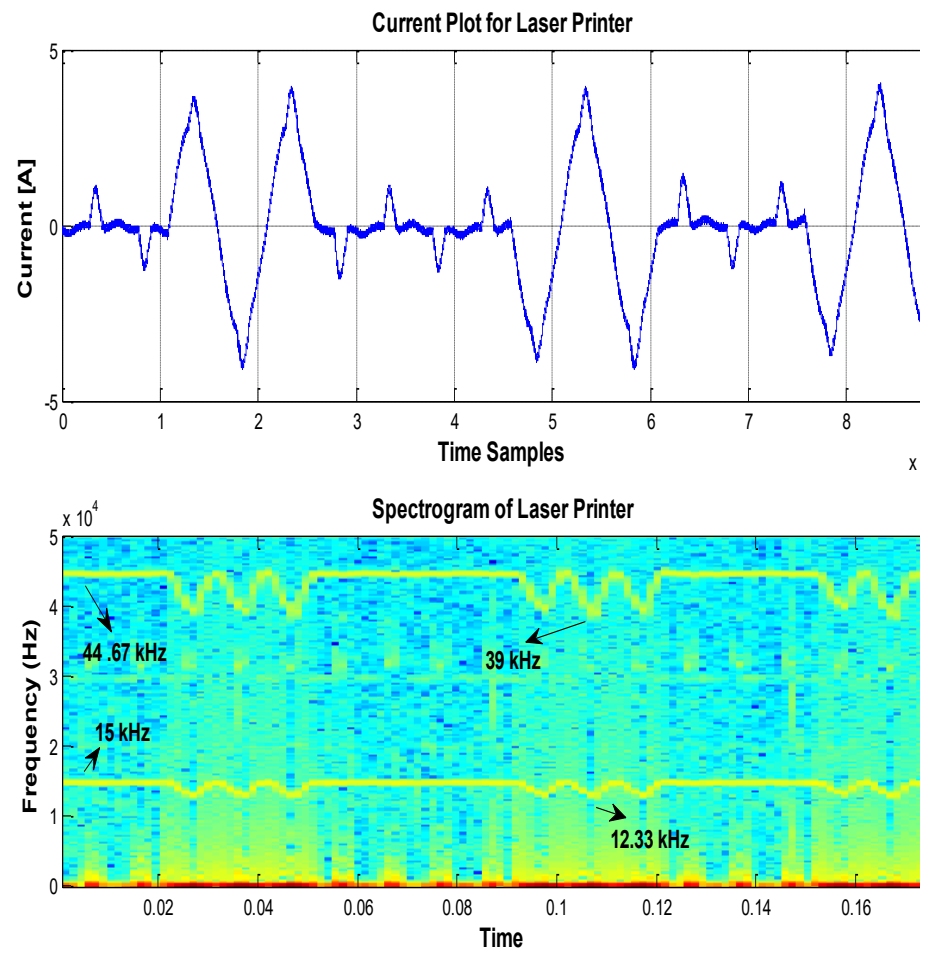

Fig 5. Spectrogram of the current Laser Printer

In figure 5 is illustrated continuous and fluctuant frequency emission at $15 \mathrm{kHz}$ and $44.67 \mathrm{kHz}$ bands. Figure 6 shows the frequency spectrum of IMF 3- IMF 5. When considering the spectrum it is comprehensively shown that IMF 3 represents the frequency component $(15.14 \mathrm{kHz})$. Furthermore, IMF 4 also shows frequency $(44.92 \mathrm{kHz})$ band.

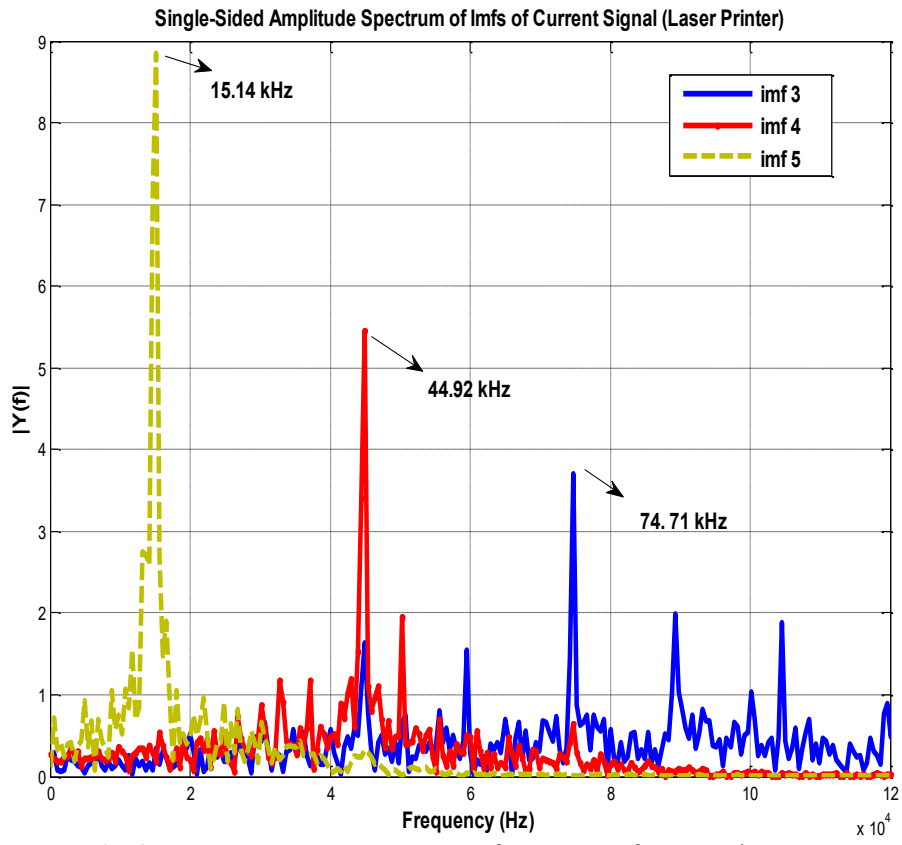

Fig 6. Frequency IMFs components for current of Laser Printer
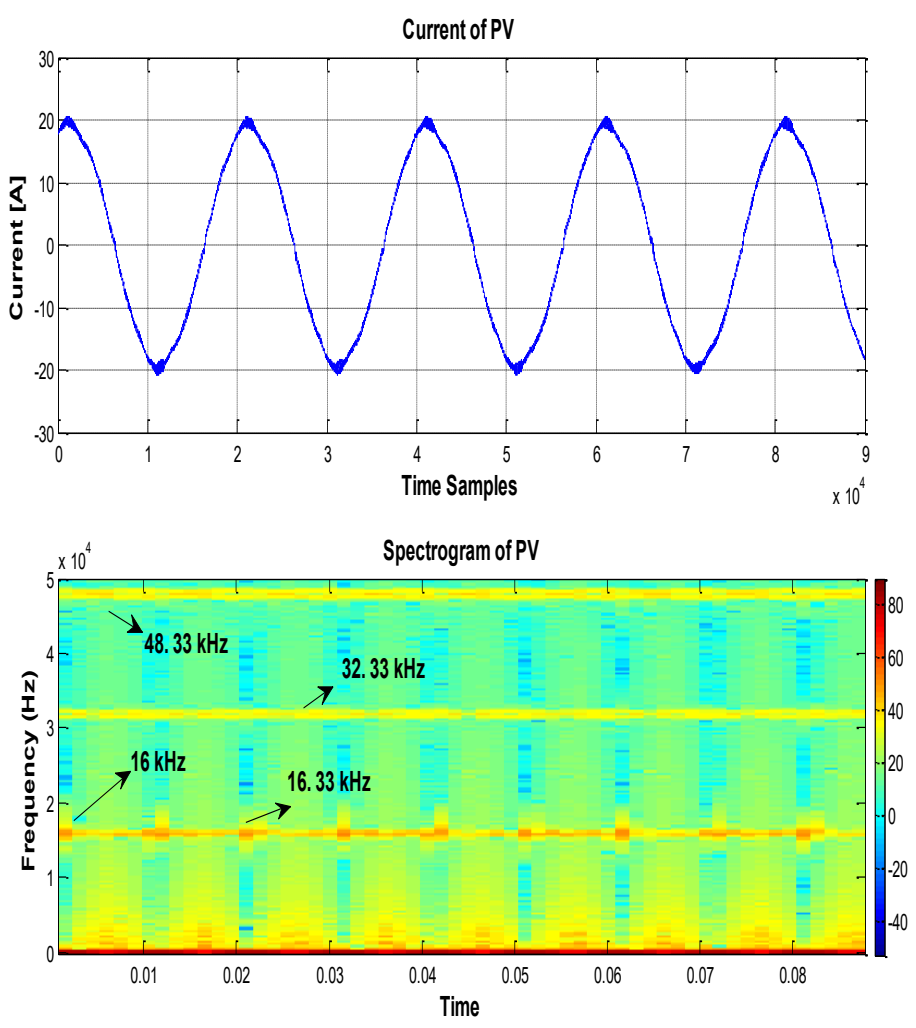

Fig 7. Spectrogram of the current power line with PV (Sampling Frequency: $1 \mathrm{MHz}$ )

In figure 7 is illustrated Continuous and fluctuant frequency emissions at $16 \mathrm{kHz}$ output PLC frequency and Daylight emission at $32 \mathrm{kHz}$ PV inverter signature bands. 

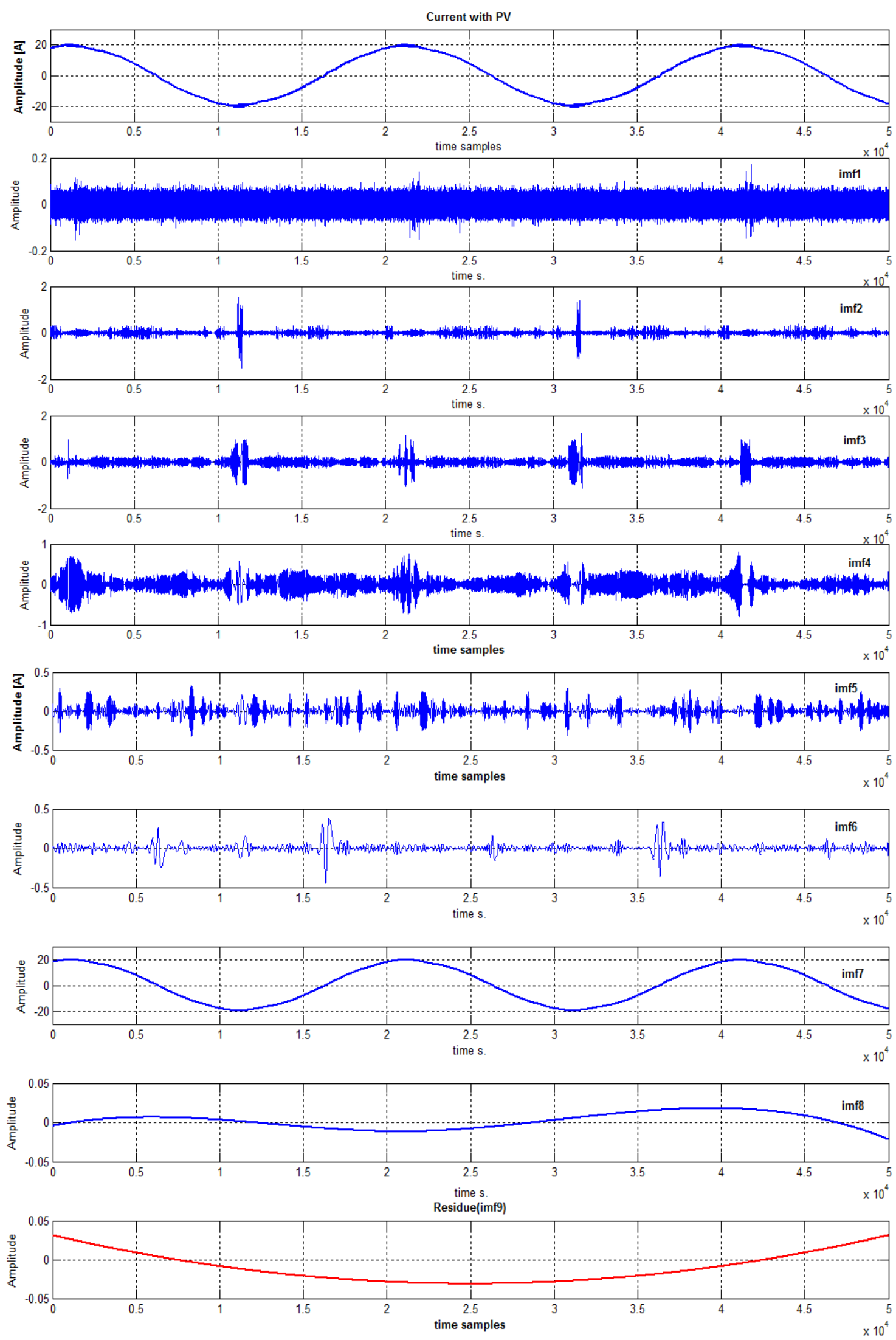

Fig 8. IMF components of PV current signal 


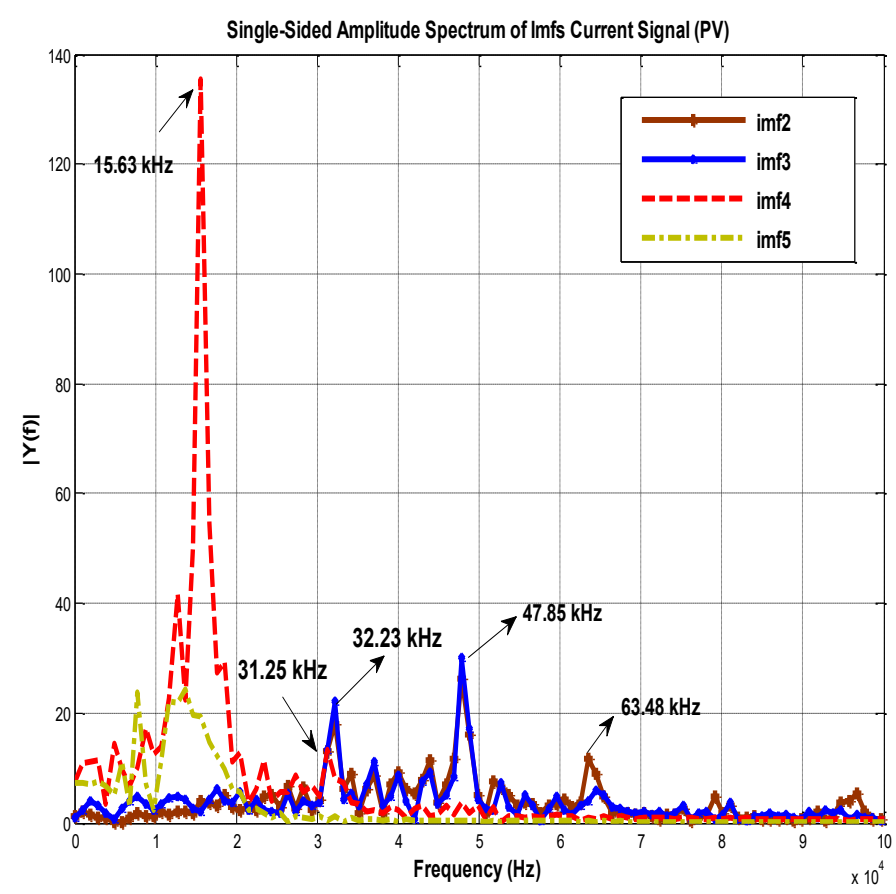

Fig 9. Frequency components of IMFs

Figure 8 shows the IMF components of PV signal. For measurements for PV, fig 9 shows frequency spectrum of IMF 2- IMF 5. When we look for the spectrum it is clearly illustrated that IMF 3 has PLC frequency component (15.63 $\mathrm{kHz}$ ). Moreover, IMF 4 also shows PV converter frequency $(32.23 \mathrm{kHz})$ band.

Table II. shows the relationship between signal and the IMFs components. IMFs are sorted from higher frequency to lower. Algorithm routine stops till the end of getting monotonic function IMF 9 called residual IMF $7(\mathrm{R}=0.9998)$ strongly related with the signal.

TABLE II. CORRELATION COEFFICIENT BETWEEN SIGNAL AND IMFS

\begin{tabular}{|c|c|}
\hline \hline & R (correlation coefficient) \\
\hline signal,imf1 & 0,0006 \\
\hline signal,imf2 & $-0,0014$ \\
\hline signal,imf3 & $-0,0005$ \\
\hline signal,imf4 & 0,0087 \\
\hline signal,imf5 & 0,0049 \\
\hline signal,imf6 & 0,0079 \\
\hline signal,imf7 & $\mathbf{0 , 9 9 9 8}$ \\
\hline signal,imf8 & 0,0511 \\
\hline signal,imf9 & 0,1524 \\
\hline \hline
\end{tabular}

\section{CONCLUSIONS}

Instead of traditional methods such as STFT, EEMD gives more accurate results, determining the PV inverter and PLC frequency bands with high exactitude. It was shown that EEMD method can be used for spectral analysis of supra- harmonics and can be also applied for pattern recognition of supra-harmonics in smart grids with $\mathrm{PV}$ systems. With the help of the proposed method supraharmonic analysis and pattern detection of them easily inquire into.

For future study, this results will discuss with another signal processing methods. Filter design for measuring supra-harmonics in smart grids will be investigated in the light of the analysis.

\section{REFERENCES}

[1] E.O.A. Larsson, M.H.J. Bollen, M.G. Wahlberg, C.M. Lundmark, and S.K. Rönnberg, Measurements of high-frequency $(2-150 \mathrm{kHz})$ distortion in low-voltage networks, IEEE Transactions on Power Delivery, Vol.25, No.3 (July 2010), pp.1749-1757.

[2] S.K. Rönnberg, M.H.J. Bollen, M. Wahlberg, Interaction between narrowband power-line communication and end-user equipment, IEEE Transactions on Power Delivery, Vol.26, No.3 (July 2011), pp.2034-2039.

[3] M. Bollen, M. Olofsson, A. Larsson, S. Rönnberg and M. Lundmark, Standards for supraharmonics (2 to $150 \mathrm{kHz}$ ), IEEE EMC Magazine, Vol.3 (2014), quarter 1, pp.114-119.

[4] S. Rönnberg, M. Wahlberg, M. Bollen, Conducted emission from a domestic customer in the frequency range 2 to $150 \mathrm{kHz}$ with different types of lighting, Int. Conf. Electricity Distribution (CIRED), Frankfurt, June 2011.

[5] A. Gil-de-Castro, S. K. Rönnberg and M. H. J. Bollen, "Harmonic interaction between an electric vehicle and different domestic equipment," in International Symposium on Electromagnetic Compatibility, Gothenburg, 2014, pp. 991-996.

[6] S. Rönnberg, M. Bollen, A. Larsson, Grid impact from PVinstallations in northern Scandinavia, Int. Conf. Electricity Distribution (CIRED), Stockholm, June 2013.

[7] Conducted emissions in the $2 \mathrm{kHz}-150 \mathrm{kHz}$ band Supra-harmonics, PQube ${ }^{\circledR}$ ApplicationNotev3.0, http://www.powersensorsltd.com/Download/AppNotes/

[8] M. Bollen, H. Hooshyar, S. Rönnberg, Spread of high frequency current emission, Int. Conf. Electricity Distribution (CIRED), Stockholm, June 2013.

[9] K.-M. Chang, “Arrhythmia ECG Noise Reduction by Ensemble Empirical Mode Decomposition”, Sensors, 10, 2010, pp. 6063 6080.

[10] N.E. Huang, Z. Shen., S.R. Long, M.L. Wu, H.H. Shih, Q. Zheng, N.C. Yen, C.C. Tung, H.H. Liu, "The empirical mode decomposition and Hilbert spectrum for nonlinear and nonstationary time series analysis", Proc. Roy. Soc. London A, Vol. 454, 1998, pp. 903-995.

[11] Z. Wu, N.E. Huang, "A study of the characteristics of white noise using the Empirical Mode Decomposition method," Proc. Roy. Soc. London A, 2002. 
[12] T.Yalcin, O.Ozgonenel, "Feature vector extraction by using empirical mode decomposition from power quality disturbances", IEEE SIU, Fethiye, Mugla, 2012.

[13] O.Ozgonenel, T. Yalcin, I. Guney, U. Kurt, “A New Classification for Power Quality Events in Distribution System", Electric Power System Research (EPSR), 95, 2013, pp. 192-199

[14] Z.Wu, N.E. Huang, "Ensemble empirical mode decomposition: a noiseassisted data analysis method", Adv. Adapt. Data. Anal., 1, 2009, pp.1-41.

[15] Z. Wang, Q. Zhu, J. Kiely, R. Luxton, "Hilbert Huang transform impedance measurement data for cellular toxicity monitoring" International Conference on Networking, Sensing and Control, 2009, pp. 767-772.

[16] ,T Yalcin, M Ozdemir, “An Implementation of Exploratory Start for Power Quality Disturbance Pattern Recognition", TRANSACTIONS ON ENVIRONMENT AND ELECTRICAL ENGINEERING, Vol 1, No 3, 2016 , pp 86-93.

[17] T. Yalcin, M Ozdemir, P. Kostyla, Z Leonowicz, "Analysis of SupraHarmonics in Smart Grids", EEEIC 2017., 6-9 June 2017 DOI: $10.1109 /$ EEEIC.2017.7977812

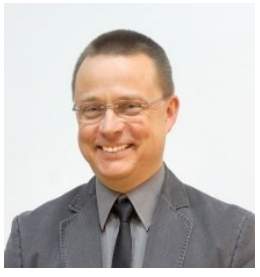

Pawel Kostyla in 1998 was awarded the title of Doctor of Science at the Wroclaw University of Science and Technology. From 1999 until now he has been working as an Assistant Professor at the Department of Electrical Engineering. $\mathrm{He}$ holds the position of Laboratory Manager of the Theoretical Electrical Engineering. Author and coauthor of publications from the author's interest areas such as artificial neural networks and methods of digital signal processing in automation and electrical engineering, algorithms of digital signal processing and electrical measurements, development and testing of new methods of measuring electrical parameters, quality of electricity.

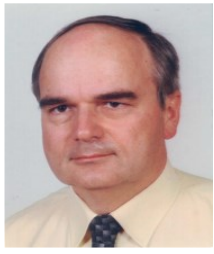

Zbigniew Leonowicz (IEEE M'03SM'12) became a Member (M) of IEEE in 2003 and a Senior Member (SM) in 2012. He received the M.Sc., Ph.D. and Habilitate Doctorate (Dr Sc.) degrees, all in Electrical Engineering, in 1997, 2001, and 2012, respectively. He has been with the Department of Electrical Engineering, Wroclaw University of Technology, since 1997 where he currently holds position of Associate Professor. His current research interests are in the areas of power quality, control and protection of power systems, renewables, industrial ecology and applications of signal processing methods in power systems.

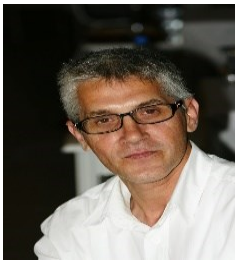

Muammer OZDEMIR received the B.Sc. and M.Sc. degrees in electrical engineering from Black Sea Technical University (KTÜ), Trabzon, Turkey, in 1988 and 1991, respectively, and the Ph.D. degree in electrical engineering from The University of Texas at Austin (UT), Austin, TX, USA, in 2002.Currently, he is an Assistant Professor with the Department of Electrical and Electronics Engineering, Ondokuz Mayıs University (OMU), Samsun, Turkey. His areas of interest are power systems harmonics, power quality, and power system analysis. 